\title{
GILLES BANDERIER, Notes contemporaines inédites sur Antoine de La Roche-Chandieu
}

\section{Filippo Fonio}

\section{(2) OpenEdition}

\section{Journals}

\section{Edizione digitale}

URL: http://journals.openedition.org/studifrancesi/33067

DOI: 10.4000/studifrancesi.33067

ISSN: 2421-5856

\section{Editore}

Rosenberg \& Sellier

\section{Edizione cartacea}

Data di pubblicazione: 1 décembre 2005

Paginazione: 630-631

ISSN: 0039-2944

\section{Notizia bibliografica digitale}

Filippo Fonio, "gllLes banderier, Notes contemporaines inédites sur Antoine de La Roche-Chandieu», Studi Francesi [Online], 147 (XLX | III) | 2005, online dal 01 novembre 2015, consultato il 19 avril 2021. URL: http://journals.openedition.org/studifrancesi/33067; DOI: https://doi.org/10.4000/studifrancesi. 33067

Questo documento è stato generato automaticamente il 19 avril 2021.

\section{(c) $($ ) $(9)$}

Studi Francesi è distribuita con Licenza Creative Commons Attribuzione - Non commerciale - Non opere derivate 4.0 Internazionale. 


\title{
GILLES BANDERIER, Notes contemporaines inédites sur Antoine de La Roche- Chandieu
}

\author{
Filippo Fonio
}

\section{NOTIZIA}

GILLES BANDERIER, Notes contemporaines inédites sur Antoine de La Roche-Chandieu, «Bibliothèque d'Humanisme et Renaissance», LXVI, 3 (2004), pp. 633-636.

1 Il ms. Tronchin 151 della Bibliothèque Publique et Universitaire de Genève contiene riflessioni e commenti anonimi all'Histoire Universelle di Agrippa d'Aubigné. Fra cui in particolare, al $f 35 \mathrm{r} / \mathrm{v}$, una nota concernente Antoine de La Roche-Chandieu, correligionario di Aubigné. L'autore di questa nota rileva un'inesattezza cronologica di Aubigné, allorché costui scrive come Antoine de La Roche-Chandieu "languì fino alla morte per il dispiacere" nell'apprendere la conversione di Henri IV al cattolicesimo. Antoine de La Roche-Chandieu muore infatti il 23 febbraio 1591, ben prima dunque del fatto in questione. 